Journal of Computer Science 8 (9): 1414-1421, 2012

ISSN 1549-3636

(C) 2012 Science Publications

\title{
Network Planning and Optimization for Multi-Hop Relay Placement in WiMAX Networks
}

\author{
Chutima Prommak and Chitapong Wechtaison \\ Institute of Engineering, School of Telecommunication Engineering \\ Suranaree University of Technology Nakhon Ratchasima, 30000, Thailand
}

\begin{abstract}
Problem statement: Wireless access networks can provide high level of quality of services at low network installation budget if the networks are planned by using proper methods. In this research, we developed efficient network planning methods for Wireless Interoperability for Microwave Access (WiMAX) networks in which the multiple hops of relay stations are deployed. Approach: An integer linear programming model was applied to the proposed problems for WiMAX networks. Our key contribution of the proposed model is two-fold. First, it aims at maximizing the quality of services of the networks, including the physical data rate and the received signal strength. Second, it aims at minimizing the cost to install the networks. The output from the proposed model is the optimal locations for the installation of the WiMAX base stations and the relay stations so that the network can accommodate user traffic demand over the target service area. Results: To evaluate the effectiveness of the proposed model, we conducted numerical experiments in the real network service environments. Conclusion: Applying our proposed model, performances of WiMAX networks can be improved in both the physical data rate and the service coverage area.
\end{abstract}

Key words: Integer Linear Programming (ILP), relay node placement problems, wireless access networks, quality of services, Wireless interoperability for microwave access (WiMAX), network cost minimization, QoS maximization

\section{INTRODUCTION}

Wireless broadband access applying the Wireless Interoperability for Microwave Access (WiMAX) technology has been a potential solution to expand the service coverage of the internet access to the area outside coverage of the wired network infrastructure. (Maraj and Imeri, 2009; Katz and Fitzek, 2009; Li et al., 2007). The multiple-hop structure of Relay Stations (RSs) in WiMAX networks is defined in the IEEE 802.16j. It allows the extension of the radio coverage from the cellular Base Stations (BSs). Our research presents the efficient methods for network planning and optimization for this type of wireless access networks.

There are some earlier studies on the performance improvement and the network planning for wireless networks including the adaptive bandwidth scheduling strategies that apply the cross-layer approach for hierarchical cellular networks (Chen et al., 2009) and the improvement for the baseband transceiver of IEEE802.16d WiMAX (Kadhim and Ismail, 2010). Moreover, there are several works devote to the development of the wireless network planning techniques. For example, the research works on the radio network planning for cellular networks are presented in (Hurley, 2000; Rawnsley and Hurley, 2000; Hamad-Ameen, 2008). The practical WiMAX planning and deployment together with the performance analysis and evaluation are presented in (Neves et al., 2007; Lannoo et al., 2007; Theodoros and Kostantinos, 2007; Marques et al., 2007). Although the results from early researches provide interesting insight from the real network performances, the networks were planned manually without the use of a mathematical formulation to optimize the network configuration.

Recent research works considered fairness of the bandwidth allocation to support multiple traffic classes in WiMAX networks (Geetha, 2011) and developed a cross layer frame work to coordinate the scheduler of the medium access control and the modulation scheme in WiMAX networks. However, the multiple-hop structure of RSs was not considered.

Although the mathematical formulation in ( $\mathrm{Yu}$ et $a l ., 2008)$ had incorporated the multiple-hop structure, the objective was to minimize the network cost of RSs and BSs installation and to minimize the path losses between the users and BS/RS locations. While the

Corresponding Author: Chutima Prommak, School of Telecommunication Engineering, Suranaree University of Technology,

111 University Avenue, Nakhon Ratchasima 30000, Thailand Tel: +66-44-224392, Fax: +66-44-224603 
contribution is important, the proposed technique could not guarantee the access quality of services. Therefore, we need more efficient planning and optimization methods for multiple-hop WiMAX networks.

In our research, we develop mathematical models for WiMAX network planning and optimization using an integer linear programming approach. Our key contribution is two-fold. First, the proposed model can maximize the quality of services of the networks, including the physical data rate and the received signal strength. Second, it can minimize the cost of network installation. The output from the proposed model is the optimal locations for the installation of the WiMAX base stations and the relay stations so that the network can accommodate user traffic demand over the target service area.

The remainder of the study is organized in four sections. The next section, Materials and Methods, provides definition of the proposed network planning problems and presents the mathematical formulations of the proposed models. Then, the Results-section demonstrates WiMAX network planning in the real service environment of Nakhon Ratchasima city in Thailand. After that the Discussion-section presents numerical comparisons and analysis of performance of networks designed by using different models. The last section, Conclusion, summarizes our research work and describes our ongoing research.

\section{MATERIALS AND METHODS}

This research focuses on the problems of cost minimization and QoS maximization for WiMAX networks. The proposed models aim to determine the optimal locations for multiple-hop structure of BSs and RSs. We applied an Integer Linear Programming (ILP) approach to formulate the WiMAX network planning problems. In particular, we developed three models for WiMAX network planning and optimization, including the BS and RS Placement Problem (BRPP), the Maximum Quality of Services problem (MQoS) and the Weighted-Maximum Quality of Services problem (W.MQoS). Table 1 describes definition of notations used in the proposed models.

BS and RS placement problem: The BS and RS placement problem, denoted as BRPP, aims at minimizing cost of $\mathrm{BS}$ and $\mathrm{RS}$ installation with consideration of the multiple-hop structure. This objective can be mathematically written in Eq. 1. This problem involves selecting optimal locations from a set of candidate sites for BSs and RSs. The multiple-hop structure of BSs and RSs allows users to directly access the BSs or indirectly connect to RSs that have direct link to BS. Specifically, the proposed model aims to determine the minimum number and the optimal locations of BSs and RSs in the target service area of the WiMAX networks so that the multiple-hop relay network configuration can be formed and the obtained networks can guarantee the quality of services, including the physical data rate and the received signal strength which define the area of the network service coverage.

Table 1: Definition of notations used in the proposed model

\begin{tabular}{|c|c|}
\hline Notations & Definition \\
\hline \multicolumn{2}{|l|}{ Sets: } \\
\hline B & $\begin{array}{l}\text { A set of locations that can install base } \\
\text { stations (BSs) }\end{array}$ \\
\hline $\mathrm{R}$ & $\begin{array}{l}\text { A set of locations that can install relay } \\
\text { stations (RSs) }\end{array}$ \\
\hline D & $\begin{array}{l}\text { A set of user locations, called demand } \\
\text { points (DPs) }\end{array}$ \\
\hline $\mathrm{T}$ & $\begin{array}{l}\text { A set of locations to evaluate signal } \\
\text { quality, called signal test points (STPs) }\end{array}$ \\
\hline \multicolumn{2}{|c|}{ Constant parameters: } \\
\hline $\mathrm{F}_{\mathrm{j}}$ & Cost to install $B S j, j \in B$ \\
\hline $\mathrm{E}_{\mathrm{i}}$ & Cost to install $R S i, i \in R$ \\
\hline $\mathrm{C}$ & Budget for network installation \\
\hline $\mathrm{P}_{\mathrm{t}}$ & $\begin{array}{l}\text { Threshold of the received signal strength } \\
\text { at STPs }\end{array}$ \\
\hline$P_{d}$ & $\begin{array}{l}\text { Threshold of the received signal strength } \\
\text { at DPs }\end{array}$ \\
\hline$P_{r}$ & $\begin{array}{l}\text { Threshold of the received signal strength } \\
\text { at RSs }\end{array}$ \\
\hline $\mathrm{P}_{\mathrm{hj}}$ & $\begin{array}{l}\text { The signal strength that a STP } h \text { receives } \\
\text { from } B S j, h \in T \text { and } j \in B\end{array}$ \\
\hline $\mathrm{P}_{\mathrm{hi}}$ & $\begin{array}{l}\text { The signal strength that a STP } h \text { receives } \\
\text { from } R S i, h \in T \text { and } i \in R\end{array}$ \\
\hline$P_{g j}$ & $\begin{array}{l}\text { The signal strength that a DP } g \text { receives } \\
\text { from } B S j, g \in D \text { and } j \in B\end{array}$ \\
\hline $\mathrm{P}_{\mathrm{gi}}$ & $\begin{array}{l}\text { The signal strength that a DP } g \text { receives } \\
\text { from RS } i, g \in D \text { and } i \in R\end{array}$ \\
\hline \multicolumn{2}{|c|}{ Decision variables: } \\
\hline$\beta_{\mathrm{j}}$ & $\begin{array}{l}\text { A binary }\{0,1\} \text { variable equals } 1 \text { if BS } \\
\text { is installed at site } j, j \in B ; 0 \text { otherwise }\end{array}$ \\
\hline$\gamma_{\mathrm{i}}$ & $\begin{array}{l}\text { A binary }\{0,1\} \text { variable equals } 1 \text { if } \\
R S \text { is installed at site } i, i \in R ; 0 \text { otherwise }\end{array}$ \\
\hline $\mathrm{u}_{\mathrm{hj}}$ & $\begin{array}{l}\text { A binary }\{0,1\} \text { variable equals } 1 \text { if } \\
\text { STP } h \text { is assigned to } B S j, h \in T \text { and } j \in B \text {; } \\
0 \text { otherwise }\end{array}$ \\
\hline $\mathrm{v}_{\mathrm{hi}}$ & $\begin{array}{l}\text { A binary }\{0,1\} \text { variable equals } 1 \text { if } \\
\text { STP } h \text { is assigned to } R S i, h \in T \text { and } \in R \\
0 \text { otherwise }\end{array}$ \\
\hline $\mathrm{X}_{\mathrm{gj}}$ & $\begin{array}{l}\text { A binary }\{0,1\} \text { variable equals } 1 \text { if } \\
\text { DP } g \text { is assigned to } B S j, g \in D \text { and } j \in B \text {; } \\
0 \text { otherwise }\end{array}$ \\
\hline $\mathrm{y}_{\mathrm{gi}}$ & $\begin{array}{l}\text { A binary }\{0,1\} \text { variable equals } 1 \text { if } \\
\text { DP } g \text { is assigned to } R S i, g \in D \text { and } i \in R \\
0 \text { otherwise }\end{array}$ \\
\hline $\mathrm{w}_{\mathrm{ij}}$ & $\begin{array}{l}\text { A binary }\{0,1\} \text { variable equals } 1 \text { if } \\
R S i \text { is assigned to } B S j, i \in R \text { and } j \in B \text {; } \\
0 \text { otherwise }\end{array}$ \\
\hline
\end{tabular}


The proposed models consider essential network requirements, including levels of the received signal strength, the physical data rate and the pattern of user distribution. Such requirements are mathematically incorporated in the proposed models via three sets of constraints, denoted $\mathrm{C} 1, \mathrm{C} 2$ and $\mathrm{C} 3$. C1 consists of five requirements as written in Eq. 2-6, ensuring the level of received signal strength in the coverage area. $\mathrm{C} 2$ consists of five requirements as written in Eq. 7-11, enforcing the required data rate at the target locations where potential users exist. C3 is a set of three requirements as written in Eq. 12-14, allowing the multiple-hop transmission from mobile users to BSs via intermediate RSs.

The following considerations are applied in the proposed models. First, the transmit power of the BSs and RSs are set at the same level. Second, expected traffic demand from a group of users is represented by Demand Points (DPs). A distribution of DPs represents the geographic locations of the potential users. Third, a set of discrete points are defined in the network area to specify the target coverage area where the quality of signal is tested. These points are called Signal Test Points (STPs). Finally, the proposed models guarantee the network coverage area and the physical data rate by enforcing the levels of signal sensitivity at DPs and STPs.

\section{BRPP Objective function:}

$$
\operatorname{Minimize} \sum_{\forall j \in B} F_{j} \beta_{j}+\sum_{\forall i \in R} E_{i} \gamma_{i}
$$

Constraints C1-Radio signal requirements: Constraint Eq. 2-6 require that the signal level received at all STPs from BS $\mathrm{j}$ or RS i must be higher than the specified level $\mathrm{P}_{\mathrm{t}}$. This set of constraints ensures the service coverage of the network.

$$
\begin{aligned}
& \sum_{\forall j \in \mathrm{B}} \mathrm{u}_{\mathrm{hj}}+\sum_{\forall i \in \mathrm{R}} \mathrm{v}_{\mathrm{hi}} \leq 1, \forall \mathrm{h} \in \mathrm{T} \\
& \mathrm{u}_{\mathrm{hj}} \leq \beta_{\mathrm{j}}, \forall \mathrm{h} \in \mathrm{T}, \mathrm{j} \in \mathrm{B} \\
& \mathrm{v}_{\mathrm{hi}} \leq \gamma_{\mathrm{i}}, \forall \mathrm{h} \in \mathrm{T}, \mathrm{i} \in \mathrm{R} \\
& \mathrm{u}_{\mathrm{hj}}\left(\mathrm{P}_{\mathrm{hj}}-\mathrm{P}_{\mathrm{t}}\right) \geq 0, \forall \mathrm{h} \in \mathrm{T}, \mathrm{j} \in \mathrm{B} \\
& \mathrm{v}_{\mathrm{hi}}\left(\mathrm{P}_{\mathrm{hi}}-\mathrm{P}_{\mathrm{t}}\right) \geq 0, \forall \mathrm{h} \in \mathrm{T}, \mathrm{i} \in \mathrm{R}
\end{aligned}
$$

Constraints C2-User access data rate requirements: Constraint Eq. 7-11 ensure the level of physical data rate that the network can serve in the service area by putting the requirement of the signal level received at all DPs from BS $\mathrm{j}$ or $\mathrm{RS} \mathrm{i}$ to be higher than the specified level $\mathrm{P}_{\mathrm{d}}$ : $\sum_{\forall \mathrm{j} \in \mathrm{B}} x_{\mathrm{gj}}+\sum_{\forall \mathrm{i} \in \mathrm{R}} \mathrm{y}_{\mathrm{gi}} \leq 1, \forall \mathrm{g} \in \mathrm{D}$

$\mathrm{x}_{\mathrm{gj}} \leq \beta_{\mathrm{j}}, \forall \mathrm{g} \in \mathrm{D}, \mathrm{j} \in \mathrm{B}$

$\mathrm{y}_{\mathrm{gi}} \leq \gamma_{\mathrm{i}}, \forall \mathrm{g} \in \mathrm{D}, \mathrm{i} \in \mathrm{R}$

$\mathrm{x}_{\mathrm{gj}}\left(\mathrm{P}_{\mathrm{gj}}-\mathrm{P}_{\mathrm{d}}\right) \geq 0, \forall \mathrm{g} \in \mathrm{D}, \mathrm{j} \in \mathrm{B}$

$\mathrm{y}_{\mathrm{gi}}\left(\mathrm{P}_{\mathrm{gi}}-\mathrm{P}_{\mathrm{d}}\right) \geq 0, \forall \mathrm{g} \in \mathrm{D}, \mathrm{i} \in \mathrm{R}$

Constraints C3-multiple-hop connections: Constraints Eq. 12-14 allow the multiple-hop path between mobile users and BSs by going through intermediate RSs. Eq. 12 ensures the connection of each $\mathrm{RS}$ that it has a link to only one BS. Eq. 13 ensures that the connected BS is installed in the network. Finally, Eq. 14 ensures the radio connectivity between RS $\mathrm{i}$ and $B S \mathrm{j}$ by requiring that the signal level received at $\mathrm{RS} i$ from BS $\mathrm{j}$ must be higher than the specified level $\mathrm{P}_{\mathrm{r}}$ :

$$
\begin{aligned}
& \sum_{\forall j \in \mathrm{B}} \mathrm{w}_{\mathrm{ij}}=\gamma_{\mathrm{i}}, \forall \mathrm{i} \in \mathrm{R} \\
& \mathrm{w}_{\mathrm{ij}} \leq \beta_{\mathrm{j}}, \forall \mathrm{i} \in \mathrm{R}, \mathrm{j} \in \mathrm{B} \\
& \mathrm{w}_{\mathrm{ij}}\left(\mathrm{P}_{\mathrm{ij}}-\mathrm{P}_{\mathrm{r}}\right) \geq 0, \forall \mathrm{j} \in \mathrm{B}, \mathrm{i} \in \mathrm{R}
\end{aligned}
$$

Maximum quality of services problem: The maximum quality of services problem, denoted as MQoS, aims to maximize quality of services in wireless access network using WiMAX technologies. The MQoS model aims at finding an optimal network configuration with multiple-hop structure that can maximize the network quality of services in term of the network coverage area and the physical data rate that mobile users can access the network. The objective of MQoS model is written in Eq. 15. We incorporate the network design requirements through a set of constraint Eq. 2-14 as described earlier. Additionally, another constraint written in Eq. 16 is applied in this model. It enforces the limitation on the network installation cost.

\section{MQoS Objective function:}

$$
\begin{aligned}
& \operatorname{Maximize} \sum_{\forall \mathrm{h} \in \mathrm{T}}\left(\sum_{\forall \mathrm{j} \in \mathrm{B}} \mathrm{u}_{\mathrm{hj}}+\sum_{\forall \mathrm{i} \in \mathrm{R}} \mathrm{v}_{\mathrm{hi}}\right) \\
& +\sum_{\forall \mathrm{g} \in \mathrm{D}}\left(\sum_{\forall j \in \mathrm{B}} \mathrm{x}_{\mathrm{gj}}+\sum_{\forall \mathrm{i} \in \mathrm{R}} \mathrm{y}_{\mathrm{gi}}\right)
\end{aligned}
$$


Constraints C4-budget limitation: Equation 16 enforces the limitation on the network installation cost which includes cost of network equipment and BS-RS construction:

$$
\sum_{\forall j \in B} \mathrm{~F}_{\mathrm{j}} \beta_{\mathrm{j}}+\sum_{\forall i \in \mathrm{R}} \mathrm{E}_{\mathrm{i}} \gamma_{\mathrm{i}} \leq \mathrm{C}
$$

Weighted-maximum quality of services problem: The weighted-maximum quality of services problem, denoted as W.MQoS, aims at maximizing quality of services by further modifying the objective function in Eq. 15 by specifying different values of weight factor to DP and STP. In particular, DPs are given higher priority than STPs. W.MQoS objective can be written in Eq. 17. The network design requirements are specified by a set of constraint Eq. 2-14 and Eq. 16 as presented earlier.

\section{W.MQoS Objective function:}

$$
\begin{aligned}
& \underset{\forall a x i m i z e}{\operatorname{Mh} \in \mathrm{T}} \mathrm{w}_{\mathrm{h}}\left(\sum_{\forall j \in \mathrm{B}} \mathrm{u}_{\mathrm{hj}}+\sum_{\forall i \in \mathrm{R}} \mathrm{v}_{\mathrm{hi}}\right) \\
& +\sum_{\forall \mathrm{g} \in \mathrm{D}} \mathrm{w}_{\mathrm{g}}\left(\sum_{\forall \mathrm{j} \in \mathrm{B}} \mathrm{x}_{\mathrm{gj}}+\sum_{\forall i \in \mathrm{R}} \mathrm{y}_{\mathrm{gi}}\right)
\end{aligned}
$$

\section{RESULTS}

The experiments of the WiMAX network planning using the proposed models (BRPP, MQoS and W.MQoS) are numerically demonstrated in the following. We consider the real network environment in downtown of Nakhon Ratchasima province, Thailand. Fig. 1 shows the service area used in our experiments.
Existing cellular BSs and new potential locations (totally 55 sites) are defined as candidate locations for BS/RS installation. Grid spacing of $250 \mathrm{~m} \times 250 \mathrm{~m}$ is used for STPs. There are 207 DPs in the target network area. The installation cost of BS and RS are $\$ 120,000$ and $\$ 40,000$, respectively. (approximate cost from Teterin et al., 2008). Other network parameters follow the WiMAX standards IEEE 802.16. Table 2 lists some parameters used in the experiments (Teterin et al., 2008). Table 3 shows the signal level requirement at the mobile users so that a certain physical data rate can be achieved (depend on techniques of modulation). Transmit power of BS and RS are set at the typical level of $35 \mathrm{dBm}$ (Rawnsley and Hurley, 2000). In case of W.MQoS model, DPs in different service areas are assigned with weight factors as shown in Table 4.

The signal level received at DPs and STPs from BSs and RSs are pre-computed and input into the network planning models. The SUI (Stanford University Interim) propagation model was used in the path-loss calculation. The SUI model was recommended by the IEEE 802.16 for path-loss calculation in WiMAX networks (Mousavi et al., 2007; Teterin et al., 2008).

The numerical experiments were implemented with the ILOG-OPL development studio. The problems were solved with CPLEX 5.2 optimization solver. The computation was run on an Intel Centrino Core2 Duo Processor $2.0 \mathrm{GHz}$ and $2 \mathrm{~GB}$ of RAM. The network performance was evaluated in term of the physical data rate guarantee and the coverage area guarantee at the specified budget limitation. The numerical results are shown in Fig. 2-4 and Table 5-8.

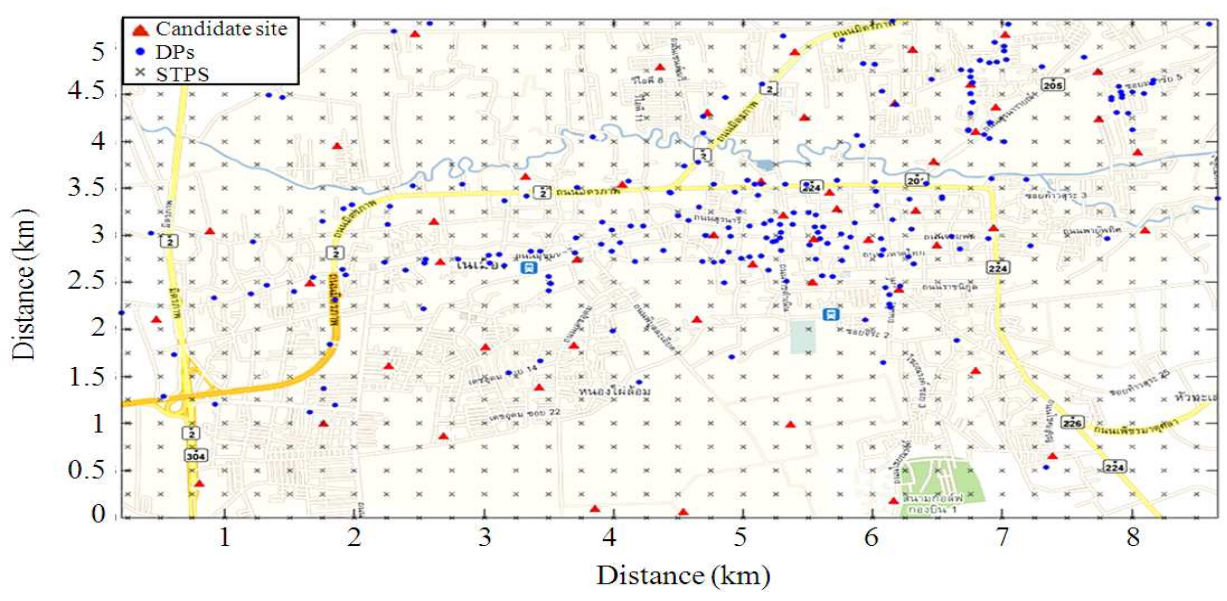

Fig. 1: Service area used in our experiments 


\section{J. Computer Sci., 8 (9): 1414-1421, 2012}

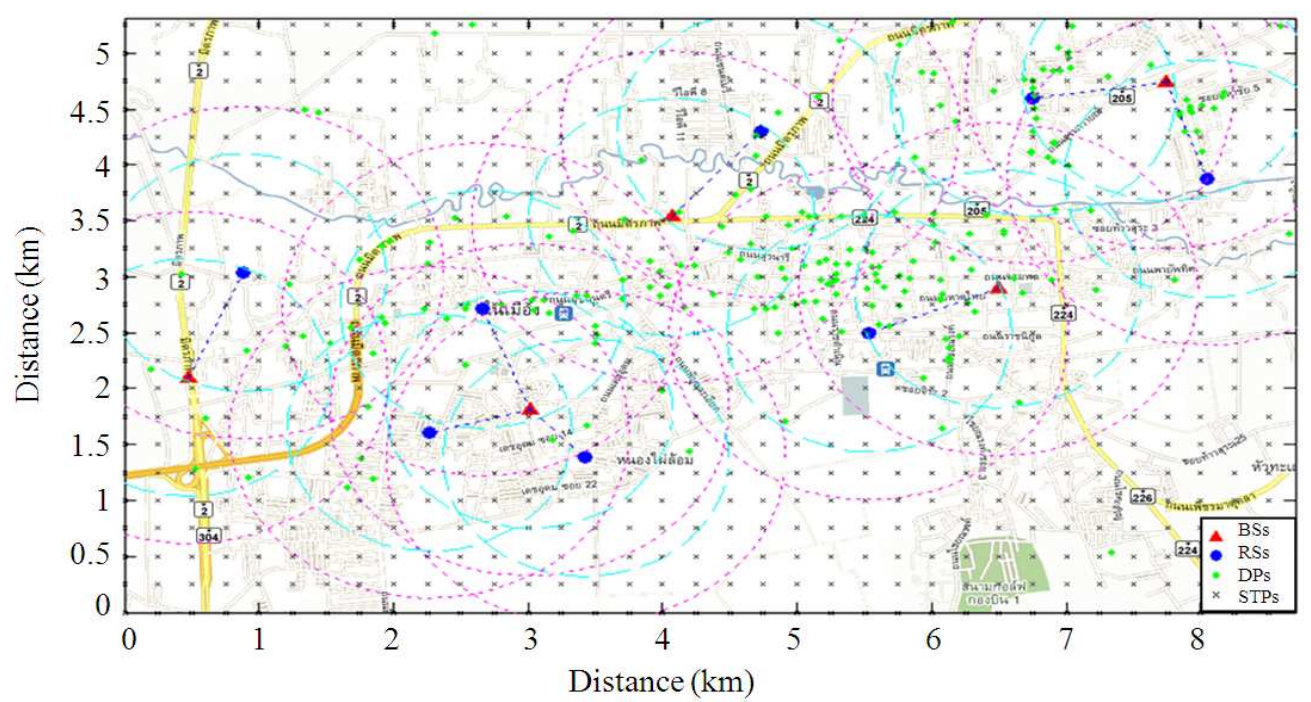

Fig. 2: Output network configuration obtained from W.MQoS model with budget of one million US\$

Table 2: Experimental parameters

\begin{tabular}{ll}
\hline Experimental parameters & Values \\
\hline Gain of transmitting antenna & $16 \mathrm{dBi}$ \\
Gain of receiving antenna & $2 \mathrm{dBi}$ \\
Transmitting power of BSs & $35 \mathrm{dBm}$ \\
Transmitting power of RSs & $35 \mathrm{dBm}$ \\
Height of BSs & $30 \mathrm{~m}$ \\
Height of RSs & $30 \mathrm{~m}$ \\
STPs' height & $2 \mathrm{~m}$ \\
Type of service environment (terrain) & $\mathrm{A}$ \\
Operating frequency & $2.5 \mathrm{GHz}$ \\
Operating bandwidth & $3.5 \mathrm{MHz}$ \\
Physical data rate requirement at DPs & $12.71 \mathrm{Mbps}$ \\
Physical data rate requirement at STPs & $5.64 \mathrm{Mbps}$ \\
BS installation cost & $120,000 \$$ \\
RS installation cost & $48,000 \$$ \\
\hline
\end{tabular}

Table 3: Threshold of received signal strength to guarantee the physical data rate (for Alvarion BreezeMAX at $3.5 \mathrm{MHz}$ )

\begin{tabular}{lll}
\hline $\begin{array}{l}\text { Received signal } \\
\text { threshold } \\
(\mathrm{dBm})\end{array}$ & $\begin{array}{l}\text { User physical } \\
\text { data rate } \\
\text { (Mbps) }\end{array}$ & $\begin{array}{l}\text { Operating } \\
\text { modulation } \\
\text { techniques }\end{array}$ \\
\hline-100 & 1.41 & BPSK 1/2 \\
-98 & 2.12 & BPSK 3/4 \\
-97 & 2.82 & QPSK 1/2 \\
-94 & 4.23 & QPSK 3/4 \\
-91 & 5.64 & QAM 16 1/2 \\
-88 & 8.47 & QAM 16 3/4 \\
-83 & 11.29 & QAM 64 2/3 \\
-82 & 12.71 & QAM 64 3/4 \\
\hline
\end{tabular}

Table 4: Weight factors assigned for DPs that are located in different service areas

\begin{tabular}{ll}
\hline Type of service areas & Weight factor $\left(\mathrm{w}_{\mathrm{g}}\right)$ \\
\hline Department store, malls & 500 \\
University, college & 500 \\
Schools & 300 \\
Hospitals & 100 \\
Dormitory, hotels & 50 \\
Government offices & 50 \\
Temples & 20 \\
Restaurants & 10 \\
\hline
\end{tabular}

Table 5: Numerical results from BRPP model

\begin{tabular}{lr}
\hline Network parameters & Value \\
\hline Installation cost (million US\$) & 1.68 \\
Number of BSs & 10.00 \\
Number of RSs & 10.00 \\
Number of DPs that can be served by the network & 207.00 \\
Number of STPs that are in network's coverage area & 770.00 \\
Guarantee physical access data rate & $100 \%$ \\
Guarantee network service coverage & $100 \%$ \\
\hline
\end{tabular}

Table 6: Comparison of numerical results (Budget 0.5 million US\$)

\begin{tabular}{lcc}
\hline Network parameters & MQoS & W.MQoS \\
\hline Installation cost (million US\$) & 0.48 & 0.48 \\
Number of BSs & 2.00 & 2.00 \\
Number of RSs & 5.00 & 5.00 \\
Number of served DPs & 156.00 & 168.00 \\
Number of served STPs & 418.00 & 361.00 \\
Guarantee user access data rate & $75.36 \%$ & $81.16 \%$ \\
Guarantee radio service coverage & $54.29 \%$ & $46.88 \%$ \\
\hline
\end{tabular}

Table 7: Numerical result comparison (budget 1.5 million US\$)

\begin{tabular}{lcc}
\hline Network parameters & MQoS & W.MQoS \\
\hline Installation cost (million US\$) & 1.48 & 1.46 \\
Number of BSs & 10.00 & 9.00 \\
Number of RSs & 6.00 & 8.00 \\
Number of served DPs & 197.00 & 207.00 \\
Number of served STPs & 768.00 & 728.00 \\
Guarantee user access data rate & $95.17 \%$ & $100.00 \%$ \\
Guarantee radio service coverage & $99.74 \%$ & $94.55 \%$ \\
\hline
\end{tabular}

Table 8: Numerical result comparison (budget 2.5 million US\$)

\begin{tabular}{lrc}
\hline Network parameters & MQoS & W.MQoS \\
\hline Installation cost (million US\$) & 2.47 & 2.47 \\
Number of BSs & 19.00 & 19.00 \\
Number of RSs & 4.00 & 4.00 \\
Number of served DPs & 207.00 & 207.00 \\
Number of served STPs & 770.00 & 770.00 \\
Guarantee user access data rate & $100 \%$ & $100 \%$ \\
Guarantee radio service coverage & $100 \%$ & $100 \%$ \\
\hline
\end{tabular}




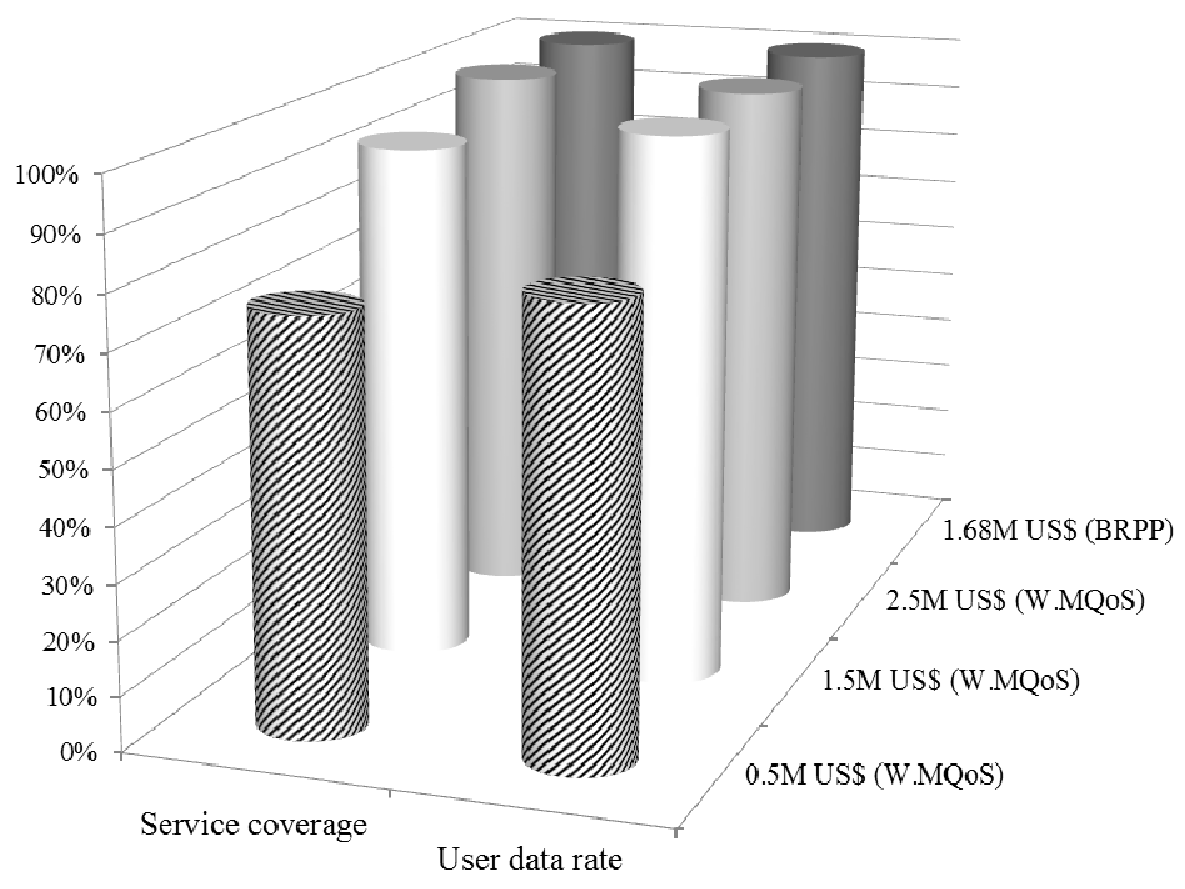

Fig. 3: Comparison of QoS at different installation budgets

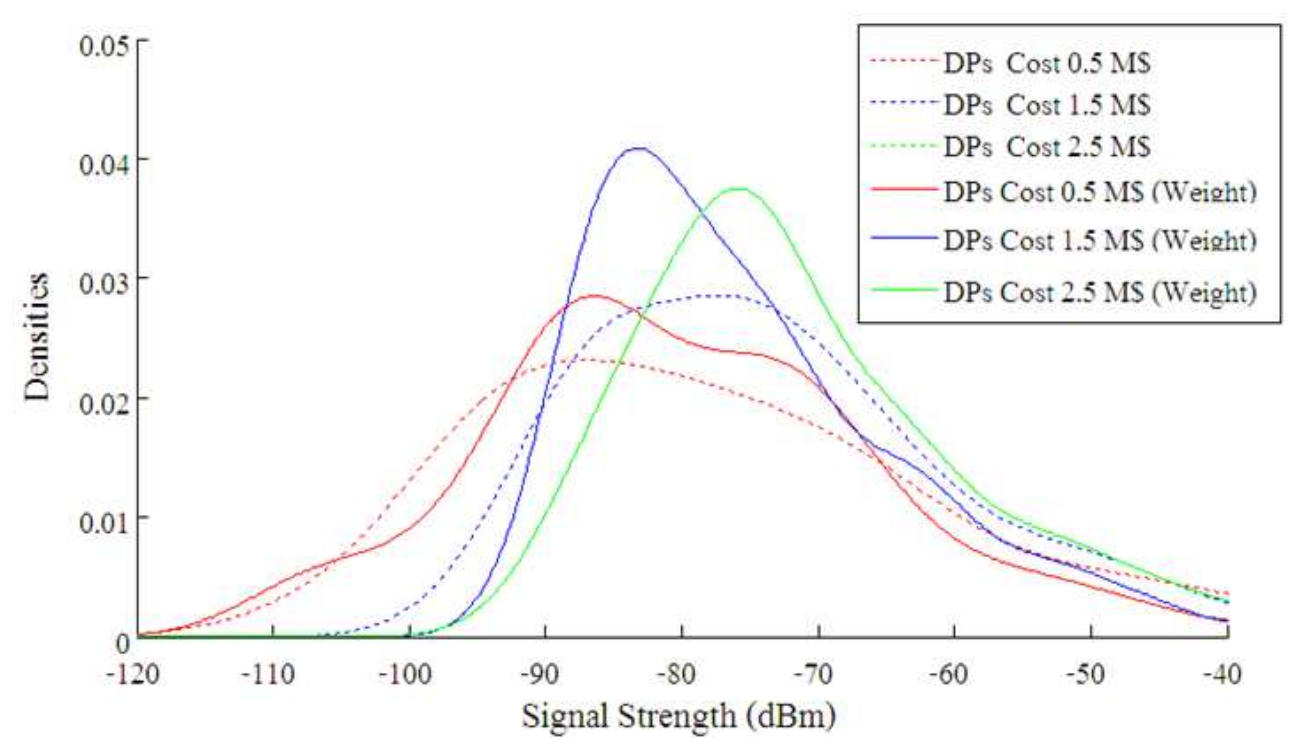

Fig. 4: PDF of signal characteristic evaluated at DPs (comparing MQoS and Weighted MQoS)

\section{DISCUSSION}

From numerical results, the following provide analysis of WiMAX network planning, including an analysis of the output network configurations, the network QoS comparisons and the signal propagation characteristics.
Analysis of the output network configuration: Figure 2 shows the resulting network configuration planned by W.MQoS model in which the budget of network installation is one million US\$. Five and eight sites are selected for BS and RS installation, respectively. The figure depicts the coverage area of BSs and RSs with blue and pink circles. From the evaluation, the output 


\section{J. Computer Sci., 8 (9): 1414-1421, 2012}

network configuration in this case can provide $100 \%$ service coverage guarantee and the minimum physical data rate guarantee.

QoS comparisons: Table 5-8 present experimental results and compare performances of networks designed by different models (BRPP, MQoS and W.MQoS). Four performance measures are considered for the comparison, including the number of installed BSs and $\mathrm{RSs}$, the total network installation cost, the percentage of service coverage guarantee and the percentage of the physical data rate guarantee. From table 5, we can see that BRPP model can achieve $100 \%$ quality of service guarantee at the network installation cost of 1.68 million US\$.

Table 6-8 compare numerical results from MQoS and W.MQoS model. From experiments using the budget limitation of 0.5 million US\$ and 1.5 million US\$, W.MQoS provide better signal quality in the area with high user density. This results in higher percentage of the physical data rate guarantee compared with the results from MQoS (as shown in Table 6-7). Consider the experiment using higher budget of 2.5 million US\$. MQoS and W.MQoS can yield $100 \%$ guarantee on the service coverage and the physical data rate (as shown in Table 8). Figure 3 compares the performance of output networks designed by W.MQoS at different installation budgets.

Signal propagation characteristics: The SUI path loss model (Mousavi et al., 2007; Teterin et al., 2008) was applied in the signal propagation analysis. Figure 4 depicts the probability density funciton of the signal strength received at the DPs of the output network designed by MQoS, compared with the results of using W.MQoS. It can be observed that the output network configuration designed by W.MQoS model yields stronger signal strength at DPs, compared with the results of using MQoS. This means W.MQoS can yield higher physical data rates to mobile users than that of MQoS.

\section{CONCLUSION}

In this study, we investigated the problems of network planning for Wireless Interoperability for Microwave Access (WiMAX) with consideration of multiple-hop structure of base stations (BSs) and relay stations (RSs). Specifically, we propose a novel integer linear programming model that can minimize the network installation cost and maximize the network performances. In particular, the proposed model determines optimal locations for BS and RS installation and derives optimal multiple-hop configuration for BSRS connections. Experimental results illustrate that the proposed WiMAX planning model can produce efficient network configurations that can improve network performances in term of the service coverage area and the physical data rate at the specified budget limitation. Our future research will apply the multiple objective functions in the network planning model to investigate tradeoff of different criteria of network performances.

\section{ACKNOWLEDGMENT}

Our research work was financially supported in part by Suranaree University of Technology (SUT), the Office of the Higher Education Commission under NRU project of Thailand and the National Research Council of Thailand (NRCT).

\section{REFERENCES}

Chen, J.S., M.W. Li, N.C. Wang and Y.F. Huang, 2009. An adaptive cross-layer bandwidth scheduling strategy for the speed-sensitive strategy in hierarchical cellular networks. Wseas Trans. Commun., 8: 545-555.

Geetha, S., 2011. Dynamic bandwidth allocation for multiple traffic classes in IEEE 802.16e WiMax networks: A petrinet approach. J. Comput. Sci., 7: 1717-1723. DOI: 10.3844/jcssp.2011.1717.1723

Hamad-Ameen, J.J., 2008. Cell planning in GSM mobile. Wseas Trans. Commun., 7: 393-398.

Hurley, S., 2000. Automatic base station selection and configuration in mobile networks. Proceeding of 52nd Vehicular Technology Conference, Sep. 2428, IEEE Xplore Press, Boston, MA, pp: 25852592. DOI: 10.1109/VETECF.2000.886795

Kadhim, M.A. and W. Ismail, 2010. Implementation of WIMAX IEEE802.16d baseband transceiver on multi-core software-defined radio platform. Wseas Trans. Commun., 9: 301-311.

Katz, M. and F. Fitzek, 2009. WiMAX Evolution: Emerging Technologies and Applications. 1st Edn., John Wiley and Sons, Hoboken, New Jersey, ISBN-10: 047069680X, pp: 502.

Lannoo, B., S. Verbrugge, J.V. Ooteghem, B. Quinart and D. Colle et al., 2007. Business scenarios for a WiMAX deployment in Belgium. Proceeding of IEEE Mobile WiMAX Symposium, Mar. 25-29, IEEE Xplore Press, Orlando, FL., pp: 132-137. DOI: 10.1109/WIMAX.2007.348708 
Li, B., Y. Qin, C.P. Low and C.L. Gwee, 2007. A survey on mobile WiMAX. IEEE Commun. Mag., 45: 70-75. DOI: 10.1109/MCOM.2007.4395368

Maraj, A. and I. Imeri, 2009. WiMAX integration in NGN network, architecture, protocols and services. Wseas Trans. Commun., 8: 708-717.

Marques, M., J. Ambrosio, C. Reis, D. Gouveia and D. Robalo et al., 2007. Design and planning of IEEE 802.16 networks. Proceeding of the IEEE 18th International Symposium on Personal, Indoor and Mobile Radio Communications Symposium, Sept. 3-7, IEEE Xplore Press, Athens, pp: 1-5. DOI: 10.1109/PIMRC.2007.4394690

Mousavi, M., S. Chamberlanda and A. Quintero, 2007. A new approach for designing WiMAX networks. Proceeding of Canadian Conference on Electrical and Computer Engineering, Apr. 22-26, IEEE Xplore Press, Vancouver, BC., pp: 487-490. DOI: 10.1109/CCECE.2007.128

Neves, P., P. Simoes, A. Gomes, L. Mario and S. Sargento et al., 2007. WiMAX for emergency services: An empirical evaluation. Proceeding of the 2007 International Conference on Next Generation Mobile Applications, Services and Technologies, Sept. 12-14, IEEE Xplore Press, Cardiff, pp: 340-345. DOI: 10.1109/NGMAST.2007.4343443
Rawnsley, R.K. and S. Hurley, 2000. Towards automatic cell planning. Proceedings of the 11th IEEE International Symposium on Personal, Indoor and Mobile Radio Communications, Sept. 18-21, IEEE Xplore Press, London, pp: 1583-1588. DOI: 10.1109/PIMRC.2000.881685

Teterin, V., S. Hurley and S.M. Allen, 2008. A staged optimization framework for cost optimized WiMax network design. Proceeding of the 4th International Conference on Wireless and Mobile Communications, Jul. 27-Aug. 1, IEEE Xplore Press, Athens, pp: 185-190. DOI: 10.1109/ICWMC.2008.46

Theodoros, T. and V. Kostantinos, 2007. WiMax network planning and system's performance evaluation. Proceeding of IEEE Wireless Communications and Networking Conference, Mar. 11-15, IEEE Xplore Press, Kowloon, pp: 1948-1953. DOI: 10.1109/WCNC.2007.365

Yu, Y., S. Murphy and L. Murphy, 2008. Planning base station and relay station locations in IEEE 802.16j multi-hop relay networks. Proceedings of the 5th IEEE Consumer Communications and Networking Conference, Jan. 10-12, IEEE Xplore Press, Las Vegas, NV., pp: 922-926. DOI: 10.1109/ccnc08.2007.214 